Methods 19 patients diagnosed with possible Indeterminate biliary stricture underwent cholangioscopy using the SpyGlass system at our institution. The quality of visualisation and the sensitivities of cytological and pathological investigations for diagnosing malignant lesions were evaluated.

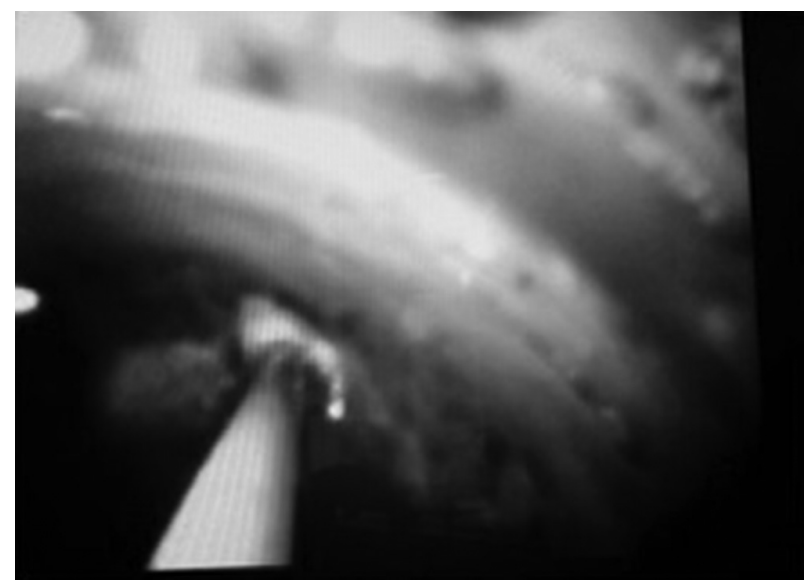

Abstract IDDF2018-ABS-0014 Figure 1 Image showing SpyGlass directed laser lithotripsy of common hepatic duct stone

Results Most patients were male (70\%), and the median age was 51 years (ranging from 21 to 72). Choledocholithiasis was the indication in $20 \%$ patients, and laser lithotripsy was performed in 3 patients. Laser lithotripsy was successful in all the patients with stone fragmentation with the extraction of stone fragmentation with biliary balloon or basket (figure 1).

In cases of undefined biliary strictures, cholangioscopy guided biopsy from the stricture helped to ascertain the aetiology in $75 \%$ cases. In post LDLT strictures, cholangioscopy was done to evaluate the morphologic pattern of the stricture. Conclusions The use of SpyGlass cholangioscopy is helpful for the management of large bile duct stones and indeterminate biliary strictures. This modality has other useful applications such as placement of guide-wire across the stricture, gall-bladder drainage. Further prospective studies are required to explore the potential benefits of this modality.

\section{IDDF2018-ABS-0015 OVER-THE-SCOPE CLIP PLACEMENT FOR THE CLOSURE OF GASTROINTESTINAL FISTULA, POSTOPERATIVE LEAKS AND REFRACTORY GASTROINTESTINAL BLEED}

Mukesh Nasa*, Narendra Choudhary, Rajesh Puri. Medanta-The Medicity, India

\subsection{6/gutjnl-2018-IDDFabstracts.64}

Background The over-the-scope clip (OTSC) has been successfully used in the closure of fistula, perforation, dehiscence, and endoscopic hemostasis. We describe our experience with the OTSC application.

Methods Between April 2014 and April 2015, seven patients underwent OTSC application (table 1). In four patients, OTSC was applied for the closure of esophageal fistula (figure 1), one had OTSC closure of persistent gastrocutaneous fistula after percutaneous endoscopic gastrostomy removal, and OTSC was applied in duodenum in two patients, for duodenal Dieulafoy's lesion after failed conventional endotherapy and massive rebleed in one and duodenal perforation in another.

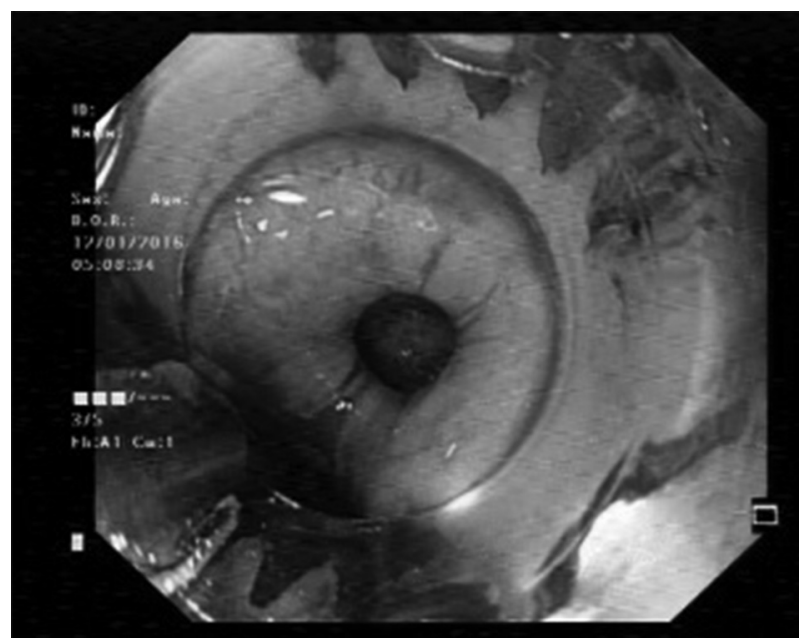

Abstract IDDF2018-ABS-0015 Figure 1 Endoscopy image showing transparent cap with OTSC over esophageal fistula opening predeployment

Abstract IDDF2018-ABS-0015 Table 1 Profile of patients

\begin{tabular}{|c|c|c|c|c|c|c|c|c|c|}
\hline & Age/Sex & Indication & $\begin{array}{c}\text { Size of } \\
\text { defect }(\mathrm{mm})\end{array}$ & $\begin{array}{l}\text { OTSC } \\
\text { type }\end{array}$ & $\begin{array}{l}\text { OTSC } \\
\text { size }\end{array}$ & $\begin{array}{c}\text { Time between diagnosis and } \\
\text { placement of OTSC(Days) }\end{array}$ & $\begin{array}{l}\text { Accessory used-Twin grasper } \\
\text { (T)/Anchor (A) }\end{array}$ & $\begin{array}{l}\text { Technical } \\
\text { success }\end{array}$ & $\begin{array}{l}\text { Clinical } \\
\text { success }\end{array}$ \\
\hline 1. & 24/Male & Cervical esophageal perforation(Bullet injury) & $12 \mathrm{~mm}$ & $\begin{array}{l}\text { OTSC- } \\
\text { a }\end{array}$ & & 40 & A & Yes & Yes \\
\hline 2. & 50/Male & $\begin{array}{l}\text { Thoracic esophageal fistula-eroding } \\
\text { tubercular node }\end{array}$ & $5 \mathrm{~mm}$ & OTSC-t & & 20 & A & Yes & Yes \\
\hline 3. & $\begin{array}{c}60 / \\
\text { Female }\end{array}$ & $\begin{array}{l}\text { Broncho-esophageal fistula due to eroding } \\
\text { tubercular node }\end{array}$ & $5 \mathrm{~mm}$ & OTSC-t & & 15 & A & Yes & Yes \\
\hline 4. & 53/Male & Duodenal perforation & $10 \mathrm{~mm}$ & OTSC- $t$ & & 2 & $\mathrm{~T}$ & Yes & Yes \\
\hline 5. & 68/Male & Gastro-cutaneous fistula & $12 \mathrm{~mm}$ & $\begin{array}{l}\text { OTSC- } \\
\text { gc }\end{array}$ & & 35 & $\mathrm{~T}$ & Yes & Yes \\
\hline 6 & $\begin{array}{c}56 / \\
\text { Female }\end{array}$ & Duodenal dieulafoy lesion & - & $\begin{array}{l}\text { OTSC- } \\
\text { a }\end{array}$ & & 1 & - & Yes & Yes \\
\hline 7 & 46/Male & $\begin{array}{l}\text { Esophago-Bronchial Fistula due to Eroding } \\
\text { tubercular lymph node }\end{array}$ & $10 \mathrm{~mm}$ & OTSC-t & & 21 & A & Yes & Yes \\
\hline
\end{tabular}


Results All procedures had technical success with no immediate complication related to OTSC application. Patients were followed up for every month with a mean duration of follow up 10.2 months. One patient with bronchoesophageal fistula had the development of another fistulous opening above the site of OTSC placement, which was successfully closed with another OTSC. One patient had superficial esophageal wall ulcer opposite the OTSC, but it healed spontaneously.

Conclusions OTSC provided safe and successful closure in a number of settings such as the closure of fistula, perforation, dehiscence.

\section{IDDF2018-ABS-0016 REMOVABLE SELF-EXPANDING METAL STENTS INSERTION FOR THE TREATMENT OF PERFORATIONS AND POSTOPERATIVE LEAKS OF THE OESOPHAGUS}

Mukesh Nasa*, Narendra Choudhary, Rajesh Puri. Medanta-The Medicity, India

\subsection{6/gutjnl-2018-IDDFabstracts.65}

Background Esophageal rupture, spontaneous or iatrogenic, is associated with significant morbidity and mortality. The current study aims at highlighting the various clinical scenarios, where esophageal fully covered self-expanding removable metal stents (FCSEMS) can be used in esophageal rupture.

Methods In patients who underwent insertion of FCSEMS between January 2013 and June 2014, all data regarding demographics, indications, insertion, removal, and outcomes were studied retrospectively (table 1). Seven patients underwent the placement of esophageal covered SEMS. Two patients had Boerhaave syndrome (figure 1), two had leak following the repair of an aortic aneurysm, one had extensive esophageal injury following transesophageal echocardiography, one had carcinoma oesophagus with tracheaesophageal fistula, and one had dehiscence of esophagogastric anastomosis.

Results Seven patients underwent the placement of esophageal covered SEMS. Two patients had Boerhaave syndrome, two had leak following the repair of an aortic aneurysm, one had extensive esophageal injury following transesophageal echocardiography, one had carcinoma oesophagus with tracheaesophageal fistula, and one had dehiscence of esophagogastric anastomosis. Stent insertion was successful in all the patients; one had stent migration which was managed endoscopically. Two patients died due to underlying illness; the rest had successful removal of stents after 8-10 weeks and good outcomes.

Conclusions Esophageal FCSEMS placement is safe and effective modality in the management of patients with esophageal rupture.

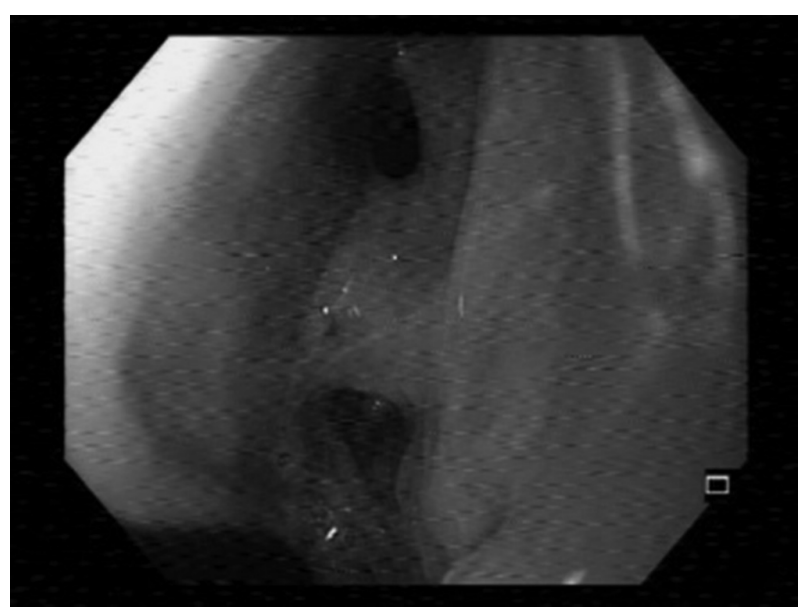

Abstract IDDF2018-ABS-0016 Figure 1

\section{IDDF2018-ABS-0017 SPLENOADRENAL SHUNT FOR NONCIRRHOTIC PORTAL HYPERTENSION}

Kalayarasan Raja*. JIPMER, India

\subsection{6/gutjnl-2018-IDDFabstracts.66}

Background Portosystemic shunt surgery is an established treatment option for preventing variceal rebleeding in patients with noncirrhotic portal hypertension $(\mathrm{NCPH})$. The proximal splenorenal shunt is a widely performed procedure in these patients. In this study, the use of adrenal vein as an alternative conduit has been investigated.

Methods A retrospective analysis of patients with NCPH who underwent proximal splenoadrenal and splenorenal shunt between 2011 and 2015 was performed. Demographic findings, aetiology of portal hypertension, clinical presentation, haematological parameters, liver function test, intraoperative findings, postoperative morbidity, and shunt patency were studied and compared between the two groups. All patients were followed up for a minimum of 12 months with Doppler

\begin{tabular}{|c|c|c|c|c|c|c|c|}
\hline Patient & $\begin{array}{l}\text { Age/ } \\
\text { Gender }\end{array}$ & History & Indication of stenting & $\begin{array}{l}\text { Interval between diagnosis of leak to placement } \\
\text { of SEMS(days) }\end{array}$ & $\begin{array}{l}\text { Length of stent } \\
\qquad(\mathrm{mm})\end{array}$ & $\begin{array}{l}\text { Removal done after } \\
\text { (weeks) }\end{array}$ & Outcome \\
\hline 1. & $44 / \mathrm{M}$ & Spontaneous distal eso rupture & Boerhaave syn & 2 & 120 & 8 & Recovery \\
\hline 2. & $68 / \mathrm{M}$ & Haemetemesis following TEE & $\begin{array}{l}\text { Mid and lower } \\
\text { esophageal tear }\end{array}$ & 1 & 120 (two stents) & 10 & Recovery \\
\hline 3. & $48 / \mathrm{M}$ & Thoracic aorta aneurysm repair & Mid-esophageal leak & 8 & 120 & - & Expired \\
\hline 4. & $60 / F$ & Spontaneous distal eso rupture & Boerhaave syn & 1 & 120 & 10 & Recovery \\
\hline 5. & $42 / \mathrm{M}$ & $\begin{array}{l}\text { Total gastrectomy with esophago- } \\
\text { jejunostomy }\end{array}$ & Anastomotic leak & 40 & 120 & - & Expired \\
\hline 6. & $44 / M$ & Thoracic aorta aneurysm repair & Esophageal leak & 2 & 120 & 8 & Recovery \\
\hline 7. & $57 / M$ & $\begin{array}{c}\text { Carcinoma oesophagus with esophago- } \\
\text { pleural fistula }\end{array}$ & Esophago-pleural fistula & 7 & 120 & 10 & Recovery \\
\hline
\end{tabular}

